\title{
LATE RESULTS OF HEART VALVE REPLACEMENT WITH THE HANCOCK II BIOPROSTHESIS
}

Tirone E. David, MD

Joan Ivanov, MSc

Sue Armstrong, MSc

Christopher M. Feindel, MD

Gideon Cohen, MD
Objective: To review the late clinical outcomes of patients who had isolated aortic or mitral valve replacement with the Hancock II bioprosthesis.

Methods: From 1982 to 1994,670 patients underwent isolated aortic valve replacement and 310 underwent isolated mitral valve replacement with the Hancock II bioprosthesis (Medtronic Inc, Minneapolis, Minn). Mean age was $65 \pm 12$ years in both groups. Most patients were in New York Heart Association functional classes III or IV, and concomitant coronary artery disease was present in $44 \%$ of patients in the aortic valve group and $41 \%$ of patients in the mitral valve group. Patients were followed up prospectively at periodic intervals. Mean follow-up was $87 \pm 45$ months in the aortic valve group and $83 \pm 50$ months in the mitral valve group, and it was $99 \%$ complete.

Results: Actuarial survival at 15 years was $47 \% \pm 3 \%$ in the aortic valve group and $30 \% \pm 5 \%$ in the mitral valve group. Older age, advanced functional class, impaired left ventricular function, active endocarditis, and coronary artery disease were independent predictors of late death. The freedom from thromboembolic complications at 15 years was $83 \% \pm 3 \%$ in the aortic and $87 \% \pm 3 \%$ in the mitral valve group. The freedom from infective endocarditis at 15 years was $96 \% \pm 1 \%$ in the aortic and $91 \% \pm 1 \%$ in the mitral valve group. At 15 years, the actuarial and actual freedom from structural valve deterioration was $81 \% \pm 5 \%$ and $90 \% \pm 3 \%$, respectively, in the aortic group and $66 \% \pm 6 \%$ and $83 \% \pm 3 \%$, respectively, in the mitral group. Younger age, mitral valve position, and poor ventricular function were independent predictors of structural valve deterioration. The freedom from repeat valve replacement at 15 years was $77 \% \pm 5 \%$ in the aortic group and $69 \% \pm$ $6 \%$ in the mitral. The vast majority of patients had functional improvement after valve replacement.

Conclusions: The Hancock II bioprosthesis has provided good clinical outcomes and is a durable valve, particularly in the aortic position in older patients. (J Thorac Cardiovasc Surg 2001;121:268-78)
From the Division of Cardiovascular Surgery of Toronto General Hospital and University of Toronto, Toronto, Ontario, Canada.

Read at the Eightieth Annual Meeting of The American Association for Thoracic Surgery, Toronto, Ontario, Canada, April 30-May 3, 2000.

Received for publication May 4, 2000; revisions requested Aug 9, 2000; revisions received Aug 31, 2000; accepted for publication Oct 12, 2000.

Address for reprints: Tirone E. David, MD, 200 Elizabeth St, EN13219, Toronto, Ontario, Canada M5G 2C4 (E-mail: tirone.david@uhn.on.ca).

Copyright @ 2001 by The American Association for Thoracic Surgery

$0022-5223 / 2001 \$ 35.00+0 \quad \mathbf{1 2 / 6 / 1 1 2 2 0 8}$

doi: $10.1067 / \mathrm{mtc} .2001 .112208$
The Hancock II bioprosthesis (Medtronic Inc,
Minneapolis, Minn) differs from its predecessors in
several aspects: the porcine aortic root is fixed with a
buffered solution of $0.625 \%$ glutaraldehyde in two
stages, an initial stage of low pressure and a late stage
of physiologic pressure; the stent is made of Delrin
resin (DuPont, Wilmington, Del) and was redesigned to
minimize mechanical stress on the cusps; and the tissue
is treated with sodium dodecyl-sulfate to retard calcifi-
cation. ${ }^{1}$ The sewing ring of the bioprosthesis for aortic
valve replacement (AVR) was designed for implanta-
tion in a supra-annular position. The first clinical 
implantation of this valve occurred in September 1982 in Toronto. Although this bioprosthetic valve has been extensively used in Canada and Europe, it was only recently approved for clinical use in the United States. The following report updates late clinical outcomes in patients who had AVR or mitral valve replacement (MVR) with the Hancock II bioprosthesis.

\section{Patients and methods}

Between September 1982 and December 1994, 670 consecutive patients underwent isolated AVR (AVR group), 310 patients underwent isolated MVR (MVR group), and 148 patients underwent aortic and mitral valve surgery with the Hancock II bioprosthesis at Toronto Western Hospital (1982 through 1989) and Toronto General Hospital (1989 through 1994). Because of the relatively small number of patients undergoing double valve surgery (many patients had one valve replaced and the other repaired), this group was excluded from this analysis.

Tables I and II summarize the preoperative clinical profiles and the operative variables of each group. Mean age was 65 \pm 12 years in AVR patients and $65 \pm 11$ years in MVR patients. Although the 980 operative procedures were divided among 12 surgeons, 2 surgeons performed approximately three quarters of the operations (493 AVR: 74\%; 243 MVR: $78 \%$ ). Patients who underwent mitral valve repair and AVR with a Hancock II bioprosthesis were excluded from the AVR group. Patients with significant coronary artery disease (CAD) on preoperative angiography underwent concomitant coronary artery bypass graft surgery.

All patients were entered into a database at the time of the operation and were followed up prospectively at periodic intervals. The recent follow-up was conducted by either mailed questionnaire or telephone interview. When patients could not be contacted via such methods, follow-up was obtained from a family physician. Follow-up of all patients was $99 \%$ complete at a mean interval of $87 \pm 45$ months (range 0-201 months) in the AVR group and $83 \pm 50$ months (range 0-195 months) in the MVR group. Six patients were lost to follow-up, 4 from the AVR group and 2 from the MVR group.

To minimize transvalvular gradients, we attempted to match patient body surface area to bioprosthetic size using guidelines based on the hemodynamic performance of the Hancock II bioprosthesis. ${ }^{2,3}$ To accomplish this, we had to enlarge the aortic anulus with a patch in $125(19 \%)$ patients undergoing AVR. In general, patch enlargement enabled insertion of valves 1 to 2 sizes larger than would have otherwise been possible without enlargement.

From 1985 to 1989 , all patients undergoing bioprosthetic valvular replacement at the two hospitals were discharged from the hospital on a regimen of daily warfarin sodium for the first 3 months postoperatively, followed by lifelong aspirin therapy. This practice was discontinued in 1990, after which only patients with bioprosthetic MVR were given warfarin for the first 3 postoperative months.
Operative survivors underwent at least one echocardiographic evaluation during the first postoperative year, along with additional evaluations in the event of cardiac or valverelated complications. Postoperative complications were prospectively monitored and analyzed according to guidelines set forth by The American Association for Thoracic Surgery. ${ }^{4}$

Outcomes. The primary outcome in this analysis was allcause mortality. Cause of death was established from hospital records or autopsy reports when available. Operative death was defined as any death in the hospital or at home within 30 days after the operation.

Bioprosthetic valve dysfunction provided a secondary outcome. This was defined as any clinically relevant valvular stenosis or insufficiency documented by Doppler echocardiography, reoperation, or autopsy. For the purpose of these evaluations, the date of reoperation, rather than the date of echocardiographic confirmation of structural valve deterioration (SVD), was considered as the failure date in patients with valve dysfunction. However, all patients who underwent reoperation had Doppler echocardiography within 90 days of their redo operation. We may, therefore, have slightly overestimated the time to SVD; however, we believe that this method of ascertaining SVD would have contributed to noise, rather than bias for subgroup comparisons.

Additional outcomes included thromboembolic events (only the first event being included in the analyses), bioprosthetic valve endocarditis, and repeat AVR or MVR.

Statistical analyses. SAS 6.12 for Windows was used for statistical analyses (SAS Institute, Inc, Cary, NC). Continuous variables are presented as mean \pm standard error unless otherwise noted.

Univariate analysis. Differences in prognostic variables between groups were evaluated by $t$ tests for continuous variables and the $\chi^{2}$ or Fisher exact test for categoric variables. The term actuarial is used in this report to describe the evaluation, not the method, of time-related data. Time-related data such as survival, freedom from reoperation, thromboembolic events, SVD, or combined valve-related events were analyzed univariately by the Kaplan-Meier method and the log-rank test.

Actual versus actuarial freedom from SVD. Actual versus actuarial freedom from SVD were also evaluated by methods previously described by Grunkemeier and colleagues. 5,6

Multivariable analysis. The preoperative variables tested for their univariate and multivariable association with the outcomes included age, sex, New York Heart Association (NYHA) functional classification, left ventricular grade $(1=$ ejection fraction $>60 \%, 2=$ ejection fraction $40-60 \%, 3=$ ejection fraction $20-39 \%, 4=$ ejection fraction $<20 \%$ ), preoperative electrocardiographic rhythm (sinus, atrial fibrillation/flutter, heart block), endocarditis, CAD, valvular lesion (stenosis, insufficiency, mixed), and previous cardiac operation. Patch aortic annuloplasty was tested in the multivariable models for the aortic position.

Operative death was evaluated multivariably by logistic regression analysis and long-term outcomes were evaluated by Cox regression analyses. For all multivariable models, the 
Table I. Clinical profile of patients

\begin{tabular}{|c|c|c|}
\hline Variable & $A V R$ & $M V R$ \\
\hline No. of patients & 670 & 310 \\
\hline \multicolumn{3}{|l|}{ Age $(y)$} \\
\hline Mean & $65 \pm 12$ & $65 \pm 11$ \\
\hline Range & $(18-86)$ & $(22-87)$ \\
\hline \multicolumn{3}{|l|}{ Sex } \\
\hline Male & $505(75)$ & $137(44)$ \\
\hline Female & $165(25)$ & $173(56)$ \\
\hline \multicolumn{3}{|l|}{ Electrocardiogram } \\
\hline Sinus rhythm & $599(89)$ & $155(50)$ \\
\hline Atrial fibrillation & $51(8)$ & $138(45)$ \\
\hline Complete heart block & $20(3)$ & $17(5)$ \\
\hline \multicolumn{3}{|l|}{ Infective endocarditis } \\
\hline Remote & $11(2)$ & $10(3)$ \\
\hline Active & $14(2)$ & $15(5)$ \\
\hline Active abscess & $10(1)$ & $4(1)$ \\
\hline \multicolumn{3}{|l|}{ NYHA functional class } \\
\hline I & $19(3)$ & $6(2)$ \\
\hline II & $157(23)$ & $23(8)$ \\
\hline III & $286(43)$ & $122(39)$ \\
\hline IV & $208(31)$ & $159(51)$ \\
\hline \multicolumn{3}{|l|}{ Previous cardiac operation } \\
\hline CABG & $20(3)$ & $25(8)$ \\
\hline AVR & $45(7)$ & $5(2)$ \\
\hline MVR & 0 & $42(14)$ \\
\hline Other & $5(1)$ & $7(2)$ \\
\hline \multicolumn{3}{|l|}{ LVEF } \\
\hline $\mathrm{LV}$ grade $1=\mathrm{EF}>0.60$ & $157(23)$ & $96(31)$ \\
\hline LV grade $2=$ EF 0.40-0.59 & $271(40)$ & $125(40)$ \\
\hline LV grade $3=$ EF 0.20-0.39 & $115(17)$ & $56(18)$ \\
\hline $\mathrm{LV}$ grade $4=\mathrm{EF}<0.20$ & $28(5)$ & $15(5)$ \\
\hline Not available & $99(15)$ & $18(6)$ \\
\hline CAD & 297 (44) & $139(45)$ \\
\hline \multicolumn{3}{|l|}{ Aortic valve lesion } \\
\hline Stenosis & $316(47)$ & 0 \\
\hline Insufficiency & $159(24)$ & $16(5)$ \\
\hline Mixed & $191(29)$ & $2(1)$ \\
\hline \multicolumn{3}{|l|}{ Mitral valve lesion } \\
\hline Stenosis & $1(0.1)$ & $56(18)$ \\
\hline Insufficiency & $11(2)$ & $194(63)$ \\
\hline Mixed & 0 & $57(18)$ \\
\hline Tricuspid valve disease & 0 & $43(14)$ \\
\hline
\end{tabular}

Numbers in parentheses are percentages unless otherwise specified. AVR, Aortic valve replacement; $M V R$, mitral valve replacement; NYHA, New York Heart Association functional class; $C A B G$, coronary artery bypass grafting; $L V$, left ventricular; $E F$, ejection fraction; $C A D$, coronary artery disease.

same model-building strategy was used: those variables with a univariate $P$ value $<.25$ or those of known biologic significance but failing to meet the critical $\alpha$ level were submitted for consideration to regression analysis via the use of stepwise selection, which combined forward selection with backward elimination, to determine the independent, multivariable predictors of each outcome. Interactions with age were tested in these models, but none was significant. The presence of CAD is a significant confounding factor in the evaluation of survival after valve surgery. We have therefore pre- sented a separate multivariable survival model for those patients without CAD.

\section{Results}

Operative and late deaths. There were $32(5 \%)$ operative deaths in the AVR group and $25(8 \%)$ operative deaths in the MVR group. Logistic regression analysis revealed advanced NYHA classification (class IV; odds ratio [OR]: 3.7; 95\% confidence interval [CI]: 2.0-6.9), active endocarditis (OR: 3.9; 95\% CI 1.6-9.1), and the presence of concomitant CAD (OR: 2.5; 95\% CI 1.4-4.6) to be associated with an increased risk of operative death in both groups. The area under the receiver-operator-characteristic curve (discrimination) for this model was 0.74; the Hosmer-Lemeshow goodness-of-fit $P$ value was .5 , indicating a significantly precise model. Valve location was not predictive of operative mortality.

A summary of the causes of late death in both groups is shown in Table III. There were 208 late deaths in the AVR group and 124 late deaths in the MVR group. Actuarial survival at 15 years was $47 \% \pm 3 \%$ in the AVR group and $30 \% \pm 5 \%$ in the MVR group (Fig 1). Among the late deaths in the AVR group, 28 (4\%) were valve-related, $81(12 \%)$ were cardiac-related (nonvalve), and $96(15 \%)$ were due to other causes. Among the late deaths in the MVR group, 24 (8\%) were valverelated, $58(19 \%)$ were cardiac-related, and $41(13 \%)$ were due to other causes. In 3 AVR patients and in 1 MVR patient, the exact cause of death was unknown.

The 15-year actuarial survival after AVR for patients less than 65 years of age was $65 \% \pm 4 \%$ and for those 65 years of age or older, $30 \% \pm 5 \%(P=.0001)$. Preoperative NYHA functional class also emerged as an important predictor of late survival. Patients with symptoms at rest (class IV) demonstrated a 15-year survival of only $36 \% \pm 6 \%$, whereas less symptomatic patients (classes I, II, and III) demonstrated a long-term survival of $52 \% \pm 4 \%(P=.0001)$. Similarly, in patients with grade 3 and 4 ventricles preoperatively, 15-year survival was only $35 \% \pm 6 \%$, in comparison with those patients with grade 1 and 2 ventricles for whom survival was $50 \% \pm 4 \%(P=.0001)$. Finally, patients without $\mathrm{CAD}$ had a 15 -year survival of $54 \% \pm 4 \%$, whereas those with $\mathrm{CAD}$ had a long-term survival of $38 \% \pm$ $5 \%(P=.0001)$.

Actuarial survival in patients after MVR who were less than 65 years of age was $43 \% \pm 8 \%$; those 65 years and older had a 15-year survival of only $20 \% \pm 7 \%(P$ $=.002$ ). MVR patients with symptoms at rest had a 15year survival of $15 \% \pm 5 \%$, compared with $45 \% \pm 8 \%$ 
Table II. Operative data

\begin{tabular}{lcc}
\hline Variable & AVR & MVR \\
\hline No. of patients & 670 & 310 \\
Tricuspid valve repair & $1(0.1)$ & $35(11)$ \\
Enlargement of aortic anulus & $125(19)$ & 0 \\
Replacement of ascending aorta & $78(12)$ & $3(1)$ \\
Coronary artery bypass & $294(43)$ & $127(41)$ \\
AVR: Hancock II size & & \\
21 & $48(7)$ & 0 \\
23 & $198(30)$ & 0 \\
25 & $208(31)$ & 0 \\
27 & $174(26)$ & 0 \\
29 & $42(6)$ & 0 \\
MVR: Hancock II size & & \\
25 & 0 & $11(4)$ \\
27 & 0 & $64(21)$ \\
29 & 0 & $91(29)$ \\
31 & 0 & $113(36)$ \\
33 & 0 & $31(10)$ \\
Aortic crossclamp time, min (mean \pm SD) & $73 \pm 27$ & $67 \pm 27$ \\
CPB time, min (mean \pm SD) & $99 \pm 36$ & $95 \pm 37$ \\
Operative mortality & $32(4.8)$ & $25(8)$ \\
\hline
\end{tabular}

Numbers in parentheses are percentages unless otherwise specified. AVR, Aortic valve replacement; $M V R$, mitral valve replacement; $S D$, Standard deviation; $C P B$, cardiopulmonary bypass.

$(P=.0001)$ for those in NYHA classes I-III. Survival at 15 years in MVR patients with poor ventricular function was only $10 \% \pm 8 \%$ compared with $36 \% \pm 6 \%$ $(P=.0001)$ for those with grade 1 or 2 left ventricular function. The presence of CAD in MVR was associated with a 15 -year survival of $20 \% \pm 7 \%$, whereas those without CAD had a survival of $37 \% \pm 7 \%(P=.003)$.

Site-specific multivariable models are presented in Tables IV (AVR) and V (MVR) for all-cause mortality, mortality in patients without CAD, and thromboembolic events. Because the number of events was relatively small for SVD, reoperation, and valve-related mortality, these multivariable models are presented in Table VI for the combined AVR plus MVR data set. In these combined models, valve site was included in the list of prognostic variables submitted for consideration to the analysis.

Freedom from valve-related mortality at 15 years was $92 \% \pm 2 \%$ in the AVR group and $86 \% \pm 3 \%$ in the MVR group. Preoperative atrial fibrillation and poor left ventricular function were independently associated with increased valve-related mortality (Table VI).

Thromboembolic events. There were no documented thromboses of the implanted Hancock bioprostheses in this series. Sixty (9\%) late thromboembolic events occurred in patients with AVR: 43 $(6.5 \%)$ were defined as strokes and $17(2.6 \%)$ as tran-
Table III. Summary of late morbidity and mortality

\begin{tabular}{lcc}
\hline Variable & $A V R$ & $M V R$ \\
\hline Late deaths & $208(31)$ & $124(40)$ \\
Causes of late death & & \\
$\quad$ Valve-related & $28(4)$ & $24(8)$ \\
$\quad$ Cardiac (non-valve related) & $81(12)$ & $58(19)$ \\
$\quad$ Non-cardiac/Non-valve & $96(15)$ & $41(13)$ \\
$\quad$ Unknown & $3(0.4)$ & $1(0.3)$ \\
SVD & $23(3)$ & $26(9)$ \\
Thromboembolism & & \\
$\quad$ Stroke & $43(7)$ & $20(7)$ \\
$\quad$ TIA & $17(3)$ & $3(1)$ \\
Reoperation at follow-up & $38(6)$ & $28(9)$ \\
Prosthetic valve endocarditis & $18(3)$ & $11(4)$ \\
Valve-related morbidity/mortality & $120(18)$ & $74(24)$ \\
\hline
\end{tabular}

$A V R$, Aortic valve replacement; $M V R$, mitral valve replacement; $S V D$, structural valve deterioration; TIA, transient ischemic attack; Late deaths, all deaths excluding operative deaths; Valve-related deaths, death from SVD, stroke, TIA, prosthetic valve endocarditis, reoperation on the bioprosthetic valve, anticoagulant-related hemorrhage, valve thrombosis, or hemolysis; Cardiac deaths, death from ischemic heart disease, congestive heart failure, or sudden death; Valve-related morbidity/mortality, morbidity or mortality caused by primary tissue failure, stroke, TIA, prosthetic valve endocarditis, reoperation on bioprosthetic valve, anticoagulant-related hemorrhage, valve thrombosis, or hemolysis.

sient cerebral ischemic attacks. Ten (23\%) of the strokes were fatal. Twenty-three $(8 \%)$ late thromboembolic events occurred in patients with MVR: 20 $(6.5 \%)$ were defined as strokes and $3(1.0 \%)$ as transient cerebral ischemic attacks. Nine $(45 \%)$ of the strokes were fatal. The actuarial freedom from thromboembolic events at 15 years was $83 \% \pm 3 \%$ in the AVR group and $87 \% \pm 3 \%$ in the MVR group. Advanced age and preoperative atrial fibrillation were associated with an increased risk of thromboembolic events by Cox regression analysis.

Bioprosthetic valve endocarditis. Bioprosthetic valve endocarditis developed in 18 (2.7\%) patients in the AVR group. Antibiotic therapy along with reoperation was undertaken in 7 patients, all of whom survived. The remaining 11 patients, none of whom survived, were treated conservatively. Nine of these patients were deemed to have inoperable disease because of one of more of the following factors: advanced age, poor ventricular function, multiorgan failure, or previous complex operation for endocarditis with multiple abscesses. In 2 patients the diagnosis of prosthetic valve endocarditis was established at autopsy. Bioprosthetic valve endocarditis developed in 11 (3.6\%) patients in the MVR group. Antibiotic therapy along with reoperation was undertaken in 4 patients, all of whom survived. The remaining 7 patients, none of whom survived, were 


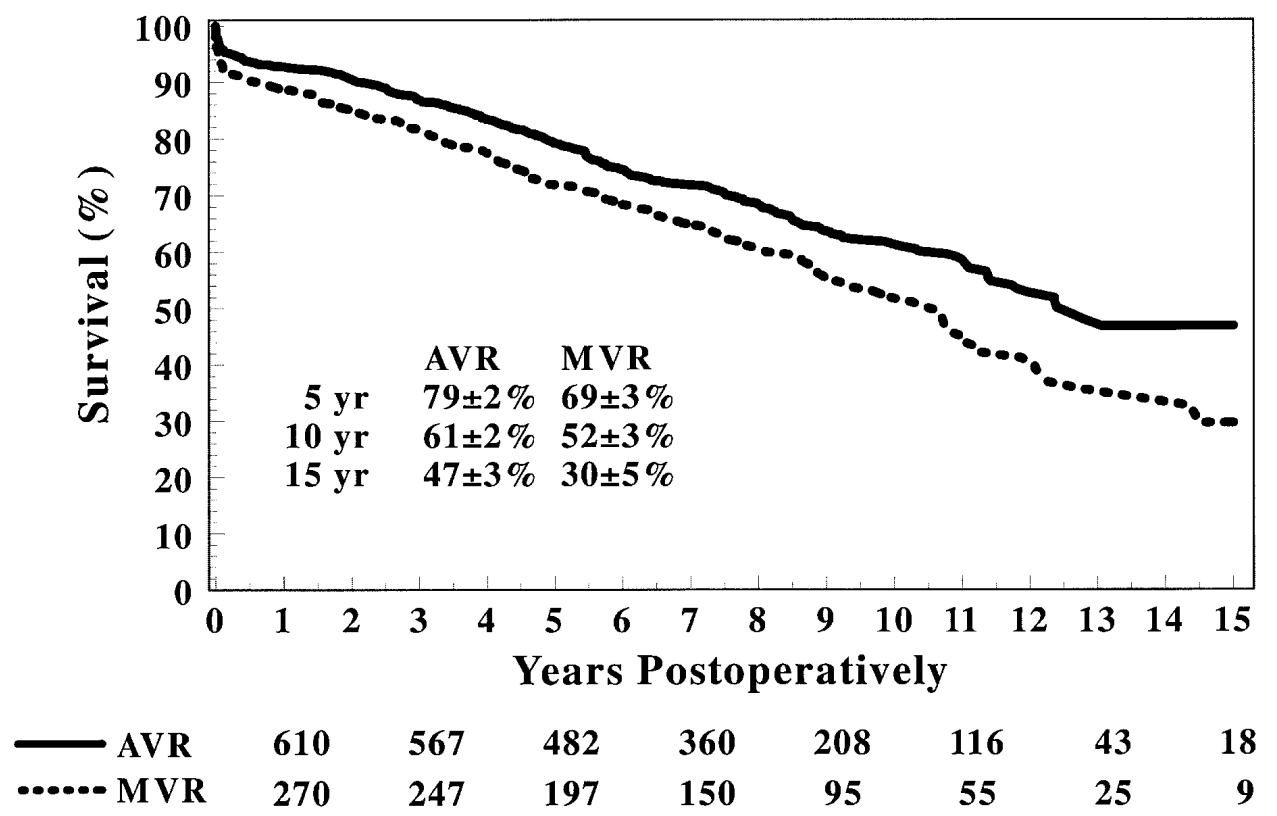

Fig 1. Actuarial (Kaplan-Meier) survival.

Table IV. Multivariable predictors of outcomes in the aortic position

\begin{tabular}{|c|c|c|c|c|}
\hline Predictor & Risk ratio & $95 \% C I$ & $\chi^{2}$ & $\mathrm{P}$ value \\
\hline \multicolumn{5}{|l|}{ All mortality } \\
\hline NYHA class IV & 1.5 & $1.1,2.0$ & 28 & 0 \\
\hline Age (per 5-year increase) & 1.2 & $1.1,1.2$ & 18.2 & 0 \\
\hline CAD & 1.4 & $1.1,1.8$ & 7.2 & .007 \\
\hline Active endocarditis & 2.6 & $1.4,4.8$ & 7.1 & .008 \\
\hline $\mathrm{LVEF}<40 \%$ & 1.5 & $1.1,2.1$ & 7.8 & .005 \\
\hline \multicolumn{5}{|c|}{ Mortality in patients without $C A D$} \\
\hline Preop AF & 3.4 & $1.9,6.1$ & 19 & 0 \\
\hline LVEF $<40 \%$ & 2.1 & $1.4,3.3$ & 15 & 0 \\
\hline Active endocarditis & 4.0 & $1.8,8.8$ & 14 & 0 \\
\hline Age (per 5-year increase) & 1.1 & $1.0,1.2$ & 5.6 & .018 \\
\hline Male sex & 1.9 & $1.2,2.9$ & 7.3 & .007 \\
\hline \multicolumn{5}{|l|}{ Thromboembolic events } \\
\hline Age (per 5-year increase) & 1.2 & $1.0,1.3$ & 6.7 & .009 \\
\hline Preop AF & 2.1 & $1.0,4.6$ & 4.1 & .042 \\
\hline
\end{tabular}

$C I$, Confidence interval; NYHA, New York Heart Association classification; $C A D$, coronary artery disease; $L V E F$, left ventricular ejection fraction; Preop AF, preoperative atrial fibrillation.

treated conservatively because they were deemed to have inoperable disease. The actuarial freedom from endocarditis at 15 years was $96 \% \pm 1 \%$ in the AVR group and $91 \% \pm 4 \%$ in the MVR group. Preoperative atrial fibrillation was the only variable that was predictive of endocarditis $(\mathrm{RR}=2.4 ; 95 \% \mathrm{CI}=1.1-5.1 ; P=$ $.02)$. However, because of the relatively small number of events for this outcome, there is a very real potential for making a type II statistical error.

SVD. Bioprosthetic valve dysfunction due to SVD occurred in 49 patients. Of the 23 patients with SVD in the AVR group, only $1(0.2 \%)$ was 65 years of age or older. Conversely, of the 26 patients with SVD in the MVR group, $8(5.0 \%)$ were 65 years of age or older. All but 1 patient with SVD in the AVR group underwent reoperation, whereas 21 of the 26 patients with SVD in the MVR group underwent reoperation. The actuarial freedom from SVD at 15 years was $81 \% \pm 5 \%$ in the AVR group and $66 \% \pm 6 \%$ in the MVR group (Fig 2). Younger age, the mitral valve position, and poor ventricular function were independently predictive of SVD (Table VI). 


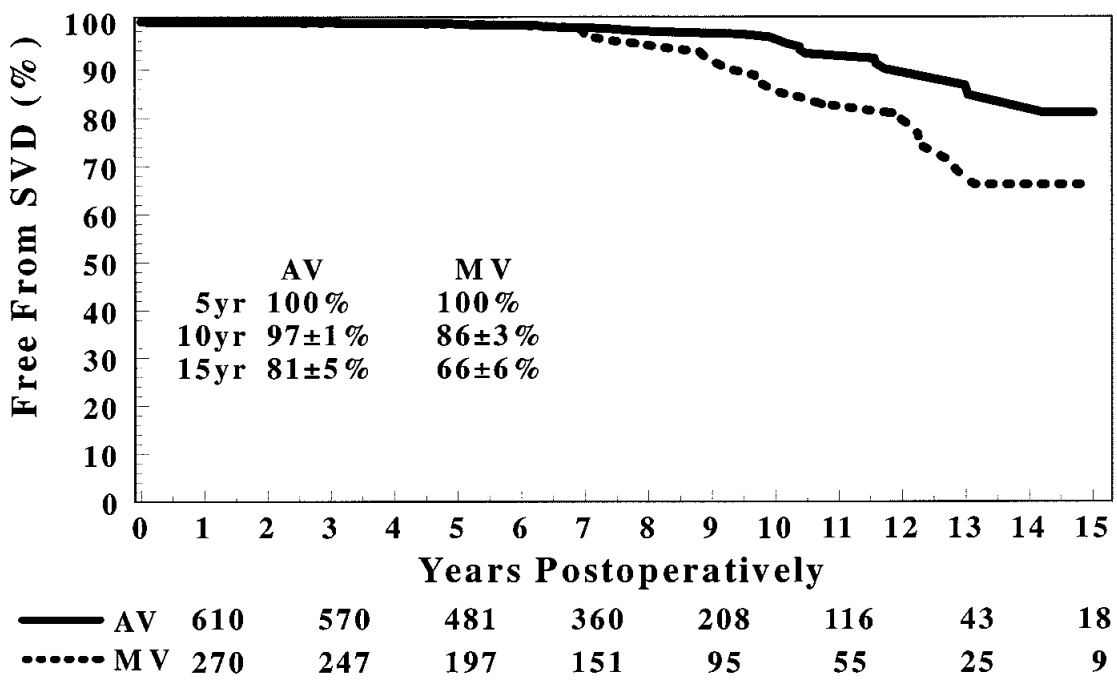

Fig 2. Actuarial (Kaplan-Meier) freedom from SVD. $A V$, Aortic valve; $M V$, mitral valve.

Table V. Multivariable predictors of outcomes in the mitral position

\begin{tabular}{|c|c|c|c|c|}
\hline Predictor & Risk ratio & $95 \% C I$ & $\chi^{2}$ & $\mathrm{P}$ value \\
\hline \multicolumn{5}{|l|}{ All mortality } \\
\hline NYHA class IV & 1.9 & $1.4,2.8$ & 30 & 0 \\
\hline Age (per 5-year increase) & 1.3 & $1.2,1.4$ & 17 & 0 \\
\hline LVEF $<40 \%$ & 2.2 & $1.5,3.1$ & 16 & 0 \\
\hline Active endocarditis & 2.7 & $1.4,5.2$ & 9 & .003 \\
\hline \multicolumn{5}{|c|}{ Mortality in patients without $C A D$} \\
\hline Age (per 5-year increase) & 1.5 & $1.3,1.8$ & 29 & 0 \\
\hline Active endocarditis & 3.9 & $1.9,8.2$ & 14 & 0 \\
\hline $\mathrm{LVEF}<40 \%$ & 2.0 & $1.0,4.1$ & 3.9 & .049 \\
\hline \multicolumn{5}{|l|}{ Thromboembolic events } \\
\hline Age (per 5-year increase) & 1.2 & $1.0,1.3$ & 6.7 & .009 \\
\hline Preop AF & 2.1 & $1.0,4.6$ & 4.1 & .042 \\
\hline
\end{tabular}

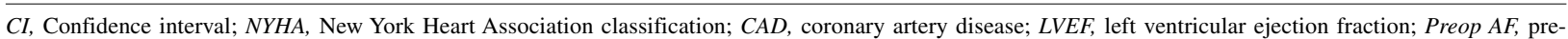
operative atrial fibrillation.

Fig 3 shows the actual freedom from SVD in the AVR group. At 15 years the actual freedom from SVD was $90 \% \pm 3 \%$; however, in patients less than 65 years of age it was $76 \% \pm 6 \%$, whereas in patients 65 years of age or older it was $100 \%$. Fig 4 shows the actual freedom from SVD in the MVR group. At 15 years the actual freedom from SVD was $83 \% \pm 3 \%$; however, in patients less than 65 years of age it was $76 \% \pm 5 \%$, whereas in patients 65 years of age or older it was $89 \% \pm 4 \%$.

Reoperation. Sixty-six patients underwent repeat valve replacement at the time of follow-up (38 AVR: 6\%; 28 MVR: 9\%) (Table III). The rate of reoperation was significantly higher in younger patients regardless of valve site. The indications for reoperation in the AVR group included ascending aortic aneurysm (2 patients), aortic dissection (1 patient), CAD (1 patient), patient-prosthesis mismatch with high systolic gradient with a normal valve (1 patient), SVD (22 patients), paravalvular leak (3 patients), bioprosthetic valve endocarditis (7 patients), and recurrent transient ischemic attacks (1 patient). There were no deaths among the 38 patients who had repeat AVR. The indications for reoperation in the MVR group were AVR (1 patient), paravalvular leak (2 patients), bioprosthetic valve endocarditis (4 patients), and SVD (21 patients). One patient in the MVR group underwent heart transplantation. Only 1 death was caused by reoperation in the MVR group. The actuarial freedom from reoperation at 15 years was $77 \% \pm 5 \%$ in the AVR group and $69 \% \pm 6 \%$ in the MVR group (Fig 5). Cox regression 


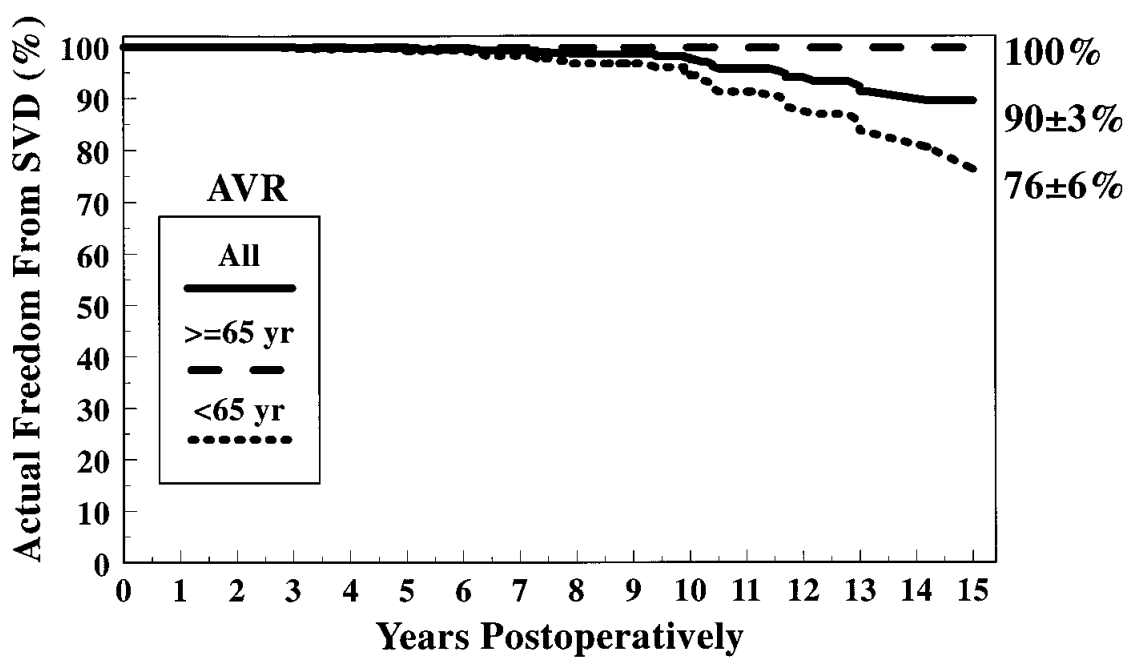

Fig 3. Actual freedom from SVD after AVR.

Table VI. Multivariable predictors of outcomes in combined data for both aortic and mitral positions

\begin{tabular}{|c|c|c|c|c|}
\hline Predictor & Risk ratio & $95 \% C I$ & $\chi^{2}$ & $\mathrm{P}$ value \\
\hline \multicolumn{5}{|l|}{ Structural valve deterioration } \\
\hline Age (per 5-year increase) & 0.8 & $0.7,0.9$ & 21 & 0 \\
\hline Mitral position & 2.2 & $1.2,3.9$ & 8.3 & .004 \\
\hline LVEF $<40 \%$ & 2.0 & $1.0,4.0$ & 4.2 & .04 \\
\hline \multicolumn{5}{|l|}{ Reoperation } \\
\hline Age (per 5-year increase) & 0.7 & $0.7,0.8$ & 56 & 0 \\
\hline $\mathrm{LVEF}<40 \%$ & 1.9 & $1.1,3.5$ & 4.9 & .027 \\
\hline \multicolumn{5}{|l|}{ Valve-related mortality } \\
\hline Age (per 5-year increase) & 1.4 & $1.1,1.6$ & 13 & 0 \\
\hline Preop AF & 2.1 & $1.2,3.8$ & 7.6 & .006 \\
\hline Active endocarditis & 3.2 & $1.0,10$ & 4.1 & .043 \\
\hline \multicolumn{5}{|c|}{ Valve-related morbidity or mortality } \\
\hline Preop AF & 1.7 & $1.2,2.4$ & 8.8 & .003 \\
\hline LVEF $<40 \%$ & 1.5 & $1.1,2.2$ & 5.4 & .02 \\
\hline
\end{tabular}

$C I$, Confidence interval; $L V E F$, left ventricular ejection fraction; Preop $A F$, preoperative atrial fibrillation.

analysis revealed younger age and poor ventricular function as independent predictors of reoperation (Table VI).

Hemorrhagic complications. Fifty-seven patients who had undergone AVR were taking warfarin sodium at the last follow-up contact because of atrial fibrillation or a previous stroke. Three of these patients had serious hemorrhagic complications. Sixty-nine patients who underwent MVR were taking warfarin sodium: 8 had serious hemorrhagic complications and 2 of them died.

Overall valve-related morbidity or mortality. The overall freedom from any valve-related morbidity or mortality at 15 years was $59 \% \pm 5 \%$ in the AVR group and $48 \% \pm 6 \%$ in the MVR group. Preoperative atrial fibrillation and poor ventricular function were predictive of valve-related morbidity or mortality (Table VI).

Late NYHA functional classification. At the time of last follow-up, 517 (53\%) patients were alive with their original Hancock II bioprostheses (387 AVR, 130 MVR). Among those who underwent AVR, 52\% were in NYHA functional class I, 30\% were in class II, $17.7 \%$ were in class III, and $0.8 \%$ were in class IV. Only 1 patient in classes III or IV had echocardiographic evidence of bioprosthetic aortic valve dysfunction (this patient was included in the analysis for SVD). Among those who underwent MVR, 38\% were in NYHA functional class I, $35 \%$ were in class II, and 


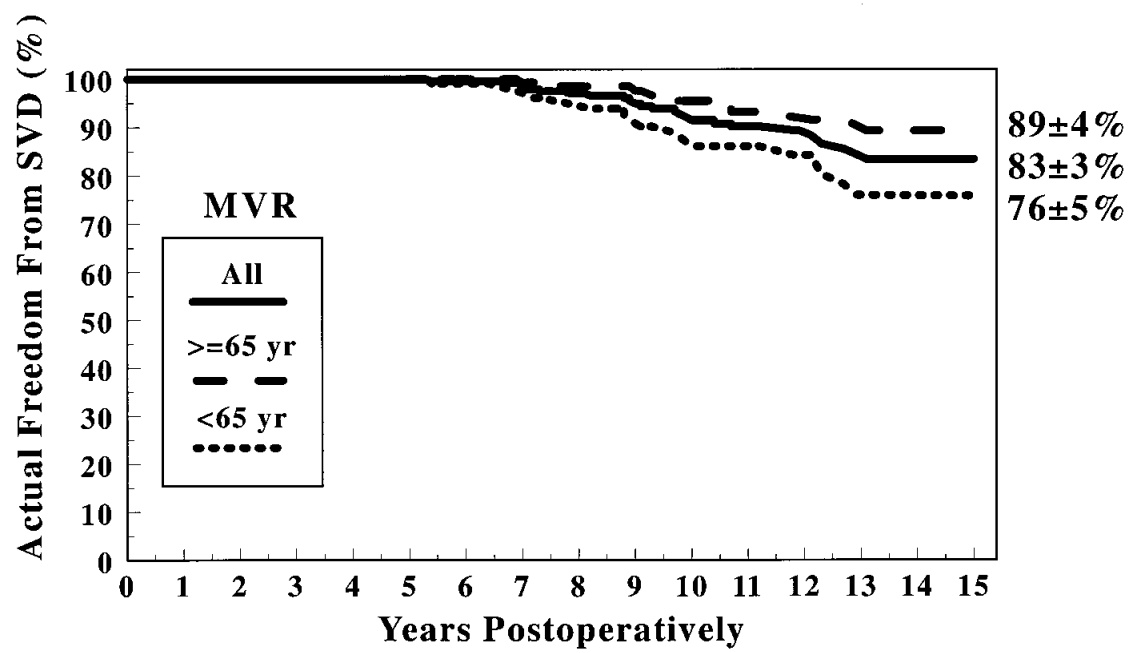

Fig 4. Actual freedom from SVD after MVR.

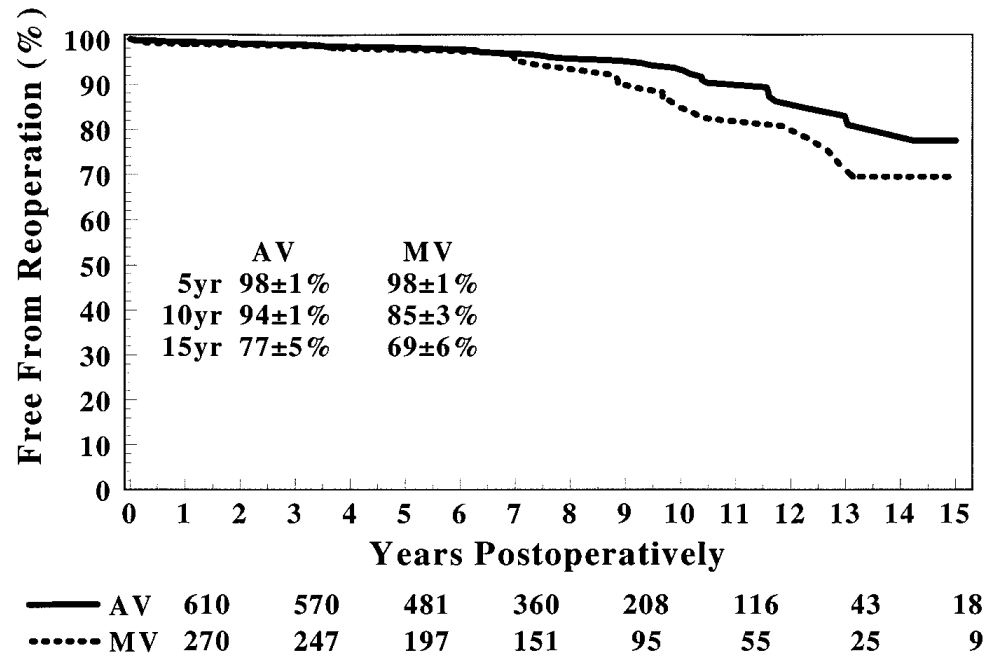

Fig 5. Actuarial (Kaplan-Meier) freedom from repeat valve replacement. $A V$, Aortic valve; $M V$, mitral valve.

$27 \%$ were in class III. Five patients in class III had echocardiographic evidence of bioprosthetic mitral valve dysfunction.

\section{Discussion}

The hemodynamic and clinical outcomes of valve replacement with the Hancock II bioprosthesis have been previously reported by our group., ${ }^{2,7}$ We present an update of our experience with this prosthesis in response to its recent approval for use in the United States.

Although numerous factors affect long-term survival after AVR, hemodynamic performance of the valve may also play a significant role. We believe that high transvalvular gradients across the aortic valve have adverse effects on the patients' symptoms, ventricular function, and ultimately survival. The 15-year survival of our patients who had AVR was better than that of other series of patients with similar age and risk factors. ${ }^{9-14}$ Indeed, a report by Ikonomidis and colleagues ${ }^{9}$ documented better long-term survival after AVR in patients with Hancock II bioprostheses than in patients with the standard Hancock valve. We believe that the hemodynamic performance of the Hancock II valve coupled with patch enlargement of the aortic anulus 
used to avoid patient-prosthesis mismatch played a role in the difference of outcomes. The smallest Hancock II bioprosthesis available for AVR is size 21, and its effective orifice area is 1.1 to $1.2 \mathrm{~cm}^{2} .^{2}$ For this reason, we believe this size of valve should not be implanted in a patient with a body surface area larger than $1.6 \mathrm{~m}^{2}$ if patient-prosthesis mismatch is to be avoided. ${ }^{2,15}$ Similarly, a Hancock II size 23 (effective orifice area of 1.3 to $1.4 \mathrm{~cm}^{2}$ ) should not be implanted in a patient with a body surface area larger than $1.7 \mathrm{~m}^{2}$. To avoid patient-prosthesis mismatch, $19 \%$ of our AVR patients had patch enlargement of the aortic anulus. As seen in Table II, only $7 \%$ of our patients had size 21 valves. Patch enlargement of the aortic anulus was not performed in these patients because their anuli could not accommodate a size 21 Hancock II bioprosthesis. Patch enlargement of the aortic anulus was not an independent predictor of any adverse event in our multivariable models. High gradients across bioprosthetic heart valves can also be a problem after MVR. A Hancock II bioprosthesis smaller than size 27 should not be implanted in the mitral position of adult patients. In this series, 11 patients had MVR with valve size 25 and none of 10 operative survivors were in NYHA functional class I postoperatively.

Long-term survival after AVR or MVR is highly dependent on the patients' ages and comorbid conditions. ${ }^{16,17}$ Multivariable analysis revealed that advanced age, NYHA functional class IV, left ventricular ejection fraction below $40 \%$, and active endocarditis were independent predictors of late mortality after AVR or MVR in our series. CAD was also a predictor of late mortality in the AVR group. According to a previous report by our group, as the number of the aforementioned risk factors increases, the long-term survival decreases after AVR. ${ }^{18}$ These variables are important to aid the surgeon in discussions with the patient about the most appropriate type of heart valve prosthesis for AVR or MVR and to estimate the probability of reoperation for SVD.

The rates of thromboembolic events and infective endocarditis after AVR or MVR with the Hancock II bioprosthesis are similar to those reported for other stented porcine and pericardial valves. ${ }^{10-14,18}$ We found that advanced age and atrial fibrillation increased the risk of thromboembolic events in both the AVR and MVR groups.

Bioprosthetic valve endocarditis was an uncommon but extremely serious valve-related complication in this series. The risk of endocarditis was highest during the first year after the operation and then decreased to a low but constant risk in both groups of patients. Our attempt to model this outcome should be interpreted with caution; we may have missed some important predictors of prosthetic valve endocarditis due to the small number of events.

Age and valve position have been shown to be the most powerful determinants of bioprosthetic valve longevity, with increased durability in the aortic position of elderly patients. ${ }^{8,10-14}$ Accordingly, in our series the Hancock II bioprosthesis was found to be more durable in the aortic than in the mitral position. This difference in durability may be due to elevated closing pressures and, thus, increased hemodynamic stresses in the mitral position. ${ }^{10}$ Older patients who had AVR with the Hancock II prosthesis were unlikely to outlive their bioprosthetic valve. In fact, only 1 of the 23 documented cases of SVD in the AVR group occurred in a patient who was 65 years of age or older. Conversely, 8 of the 26 cases of SVD in the MVR group occurred in patients 65 years of age or older. Therefore, our presentation of actual freedom from SVD using the age cut-point of less than or greater than 65 years (Figs 3 and 4) is for illustrative purposes only. In our multivariable models of SVD, we used age as a continuous variable and found that younger age, as well as the mitral site and ventricular dysfunction, were independently associated with an increased risk of SVD. The actual freedom from SVD at 15 years was $90 \%$ in the AVR group and $83 \%$ in the MVR group. Valves in the mitral position began to fail 6 years postoperatively, whereas valves in the aortic position did not begin to fail until 9 years postoperatively. Although younger patients had a higher prevalence of reoperation at follow-up, they did not demonstrate an increased frequency of valve-related deaths, owing in large part to the fact that all but 1 patient with SVD underwent successful reoperations.

A comparison of clinical outcomes of patients who had Hancock bioprostheses demonstrated the Hancock II model to be a more durable porcine valve. ${ }^{9}$ This difference is likely due to improved stent design and porcine aortic valve treatment. ${ }^{1}$ The Hancock II valve is at least as durable as the second-generation pericardial valves such as the Carpentier-Edwards Perimount prosthesis (Baxter Healthcare Corp, Edwards Division, Santa Ana, Calif). ${ }^{13,14}$ Banbury and colleagues ${ }^{14}$ reported an actuarial freedom from SVD at 12 years of 82\% after AVR with the Carpentier-Edwards pericardial valve in a patient-population whose mean age was 65 years. Poirier and colleagues ${ }^{13}$ reported an actuarial freedom from SVD at 14 years of $80 \%$ after AVR. The freedom from SVD in our patients who had AVR was better than in those two reports in a patient population 
of similar age. In the mitral position, the freedom from SVD for the Carpentier-Edwards pericardial valve was $81 \% \pm 7 \%$ at 10 years in the series reported by Poirier and associates ${ }^{13}$ and approximately $85 \%$ in a multicenter study reported by Marchand and colleagues. ${ }^{18}$ The freedom from SVD in the mitral position in our series was similar to those reported for the CarpentierEdwards pericardial valve.

Although this study confirms the favorable late results of the Hancock II bioprosthesis at our institution, its inherent limitations are those that apply to any observational outcomes analysis. Event rates were relatively small for some outcomes, which jeopardized the statistical power of some of our multivariable models (for example, we may have failed to identify an important predictor variable as significant). Nonetheless, the clinical outcomes with this bioprosthetic valve were very good. Furthermore, the durability of the Hancock II valve has been excellent, particularly in the aortic position and in patients 65 years of age or older. In view of the aforementioned, the Hancock II bioprosthesis offers an excellent option for tissue valve replacement.

\section{REFERENCES}

1. Wright JTM, Eberhardt CE, Gibbs ML, Saul M, Gilpin CB. Hancock II-an improved bioprosthesis. In: Cohn LH, Gallucci V, editors. Cardiac bioprostheses. New York: Yorke Medical Books; 1982. p. 425-44.

2. David TE, Armstrong S, Sun Z. Clinical and hemodynamic assessment of the Hancock II bioprosthesis. Ann Thorac Surg 1992;54:661-8.

3. David TE, Uden DE. Aortic valve replacement in adult patients with small aortic annuli. Ann Thorac Surg 1983;36:577-83.

4. Edmunds LH, Clark RE, Cohn LH, Miller DC, Weisel RD. Guidelines for reporting morbidity and mortality after cardiac valvular operations. J Thorac Cardiovasc Surg 1996;112:708-11.

5. Grunkemeier GL, Jamieson WR, Miller DC, Starr A. Actuarial versus actual risk of porcine structural valve deterioration. J Thorac Cardiovasc Surg 1994;108:709-18.

6. Grunkemeier GL, Anderson RP, Miller DC, Starr A. Time-related analysis of nonfatal heart valve complications: cumulative incidence (actual) versus Kaplan-Meier (actuarial). Circulation 1997;96(Suppl):II-70-74.

7. David TE, Armstrong S, Sun Z. The Hancock II bioprosthesis at 10 years. Ann Thorac Surg 1995;60:S229-34.

8. David TE, Armstrong S, Sun Z. The Hancock II bioprosthesis at 12 years. Ann Thorac Surg 1998;66:S95-8.

9. Ikonomidis JS, Ivanov J, Miller DC, Armstrong S, David TE. Improved durability with the new Hancock II bioprosthesis [abstract]. Circulation 1999;100(Suppl):I-525.

10. Jamieson WRE, Allen P, Miyagishima RT, Gerein AN, Munro AI, Burr LH, et al. The Carpentier-Edwards standard porcine bioprosthesis: a first-generation tissue valve with excellent longterm clinical performance. J Thorac Cardiovasc Surg 1990;99:543-61.
11. Glower DD, Landolfo KP, Cheruvu S, Cen YY, Harrison JK, Bashore TM, et al. Determinants of 15-year outcome with 1119 standard Carpentier-Edwards porcine valves. Ann Thorac Surg 1998;66:S44-8.

12. Jamieson WRE, Burr LH, Munro AI, Miyagishima RT. Carpentier-Edwards standard porcine bioprosthesis: a 21 year experience. Ann Thorac Surg 1998;66:S40-3.

13. Poirier NC, Pelletier LC, Pellerin M, Carrier M. 15-year experience with the Carpentier-Edwards pericardial bioprosthesis. Ann Thorac Surg 1998;66:S57-61.

14. Banbury MK, Cosgrove DM III, Lytle BW, Smedira NG, Sabik JF, Saunders CR. Long-term results of the Carpentier-Edwards pericardial aortic valve: a 12-year follow-up. Ann Thorac Surg 1998;66:S73-6.

15. Dumesnil JG, Yoganathan A. Valve prosthesis hemodynamics and the problem of high transprosthetic pressure gradients. Eur $\mathbf{J}$ Cardiothorac Surg 1992;6(suppl 1):534-7.

16. Jones EL, Weintraub WS, Craver JM, Guyton RA, Shen Y. Interaction of age and coronary artery disease after valve replacement: implications for valve selection. Ann Thorac Surg 1994;58:378-85.

17. Cohen G, David TE, Ivanov J, Armstrong S, Feindel CM. Impact of coronary artery disease, age, and other comorbid factors on late outcome after bioprosthetic aortic valve replacement. J Thorac Cardiovasc Surg 1999;117:273-84.

18. Marchand M, Aupart M, Norton R, Goldsmith IR, Pelletier C, Pellerin $\mathrm{M}$, et al. Twelve-year experience with CarpentierEdwards Perimount pericardial valve in the mitral position: a multicenter study. J Heart Valve Dis 1998;7:292-8.

\section{Discussion}

Dr W. R. Eric Jamieson (Vancouver, British Columbia, Canada). I congratulate you on an excellent series of patients and excellent analysis. Your conclusions are that this secondgeneration, supra-annular, essentially low-pressure fixed bioprosthesis is providing extended durability, particularly in the aortic position and particularly in patients who are older than 65 years of age. These are not necessarily all elderly as we probably classify them today; age 75 years is probably now considered elderly.

One of the important aspects of this series is that it can serve as a benchmark for comparison not only with the firstgeneration bioprostheses, but also with other second-generation bioprostheses, namely, the Edwards Supra-Annular bioprosthesis (Baxter) and the St Jude Medical Biocor bioprosthesis (St Jude Medical, Inc, St Paul, Minn). This will allow us to determine those factors that are improved in these prostheses that will contribute to improved durability. Is it tissue preservation? Is it stent design? These are very important factors with regard to improved durability.

The other important contribution is that the authors have used the cumulative incidence, or actual analysis, looking particularly at SVD. This method has been popularized by Dr Gary Grunkemeier from Portland in collaboration with Stanford University and the University of British Columbia. This method provides a more realistic evaluation of the influence of SVD on overall valve performance and information that can be supplied to patients. 
I have a few comments and questions.

Have you considered using the actual method to look at valve-related mortality and morbidity-not as you have defined morbidity, but rather as permanent impairment from thromboembolism, endocarditis, or hemorrhage-also valverelated reoperation? It is conceivable that this kind of information is most important for us as surgeons, for our cardiology colleagues, and specifically for our patients. The patients want to know their risk of dying from this valve, of sustaining permanent impairment, and of requiring reoperation.

Our group is currently collaborating with Dr David's to assess some of my concerns regarding this prosthesis and its contribution in conjunction with our experience with secondgeneration prostheses. This study will also serve as a landmark for the current third-generation prostheses and the stented bioprostheses and their contributions in improving clinical performance and durability of prostheses.

Dr Cohen. Thank you very much, Dr Jamieson. I will address your second comment first. I agree with you completely regarding the merits of an actual versus an actuarial analysis. As you alluded to in your discussion, the actual risk or cumulative incidence is likely of greater relevance to both patients and surgeons alike. Since it is often not possible to follow up all patients until their death, the actuarial method estimates the event-free probability for a population in which death has been completely eliminated. However, what is of great interest for counseling purposes, as well as for expense planning, is the risk of an event occurring during the lifetime of a patient. For the purposes of this article, we chose only to analyze freedom from SVD via this method. However, I agree that application of such an analytical method to other parameters including thromboembolic complications, hemorrhagic complications, endocarditis, and reoperation is equally important. Perhaps we will pursue this in the future. With regard to your comments concerning a comparison with other second-generation porcine valves including the SAV, I think you will agree that the Hancock II valve is to the Hancock valve what the Carpentier-Edwards $\mathrm{SAV}$ is to the $\mathrm{CE}$ Standard valve, namely, an improved version of a first-generation porcine valve. However, in contrast to reports from your group, in which you found no differences in durability between the SAV and Standard valves at 15 years, in a collaborative effort with Dr Craig Miller's group in Stanford, we were able to demonstrate a dramatic improvement in freedom from SVD, reoperation, and valve-related morbidity and mortality with the Hancock II versus the Hancock I valve. Although the factors contributing to this profound improvement are difficult to ascertain, the Hancock II has undergone a number of design alterations aimed at improving its overall performance in comparison to the Hancock I. These include the use of a stent manufactured from the polymer Delrin, which is more flexible, more durable, and more creep resistant than previous stents; the application of the calcium retardant T6; the new supra-annular design; and the removal of the porcine septal muscle shelf to maximize the area available for flow. Now, can such findings be extrapolated to conclude a superiority of the Hancock II over other second-generation valves? Obviously not. This can only be determined with a properly designed study involving a head-to-head comparison of similar patient groups.

Dr Verdi DiSesa (Chicago, Ill). Did you use anticoagulants in any of these patients?

Dr Cohen. Until 1989, all of our patients undergoing bioprosthetic AVR and MVR received warfarin sodium (Coumadin) for 3 months postoperatively, after which warfarin was discontinued and antiplatelet therapy initiated. This practice changed in 1990, such that AVR patients no longer received warfarin, whereas MVR continued receiving warfarin for 3 months. Currently, the bioprosthetic AVR patients receive only antiplatelet therapy, which is usually initiated on the first postoperative day, unless, of course, other indications for warfarin therapy exist, such as atrial fibrillation.

Dr DiSesa. How many had chronic atrial fibrillation and therefore had long-term anticoagulation?

Dr Cohen. Unfortunately, I cannot recall the exact numbers. However, I would say that the percentage of patients with chronic atrial fibrillation was in the range of $10 \%$ in the AVR group and $45 \%$ in the MVR group.

Dr DiSesa. My patients whose mitral valves cannot be repaired usually have atrial fibrillation or other conditions requiring anticoagulation. Therefore, the old-style pig valves for MVR are not often an option. Do you think this valve has been incrementally improved enough, especially in the younger patients, that it is a real option for MVR?

Dr Cohen. Regarding the superiority of the Hancock II valve in the mitral position, I can only comment on improvements with respect to the Hancock I valve. In our collaborative studies with the Stanford group, although the Hancock II cohort had a higher prevalence of older patients, as well as patients in preoperative NYHA functional class IV, use of the Hancock I valve was found to be the most significant independent predictor of SVD and death. Moreover, propensity scores suggested an improved durability of the Hancock II mitral valve versus the Hancock I mitral valve. We do indeed believe that this valve is incrementally superior in the mitral position. 